\title{
Kemampuan Berfikir Kritis Matematis Siswa dengan Menggunakan Model Collaborative Learning dengan Pendekatan Open-Ended Berbantuan Media Macroflash 8
}

\author{
Ika Nurjanah $^{1 *}$, Rida Fironika Kusumadewi ${ }^{2}$, Nuhyal Ulia ${ }^{3}$ \\ ${ }_{1,2,3}$ Universitas Islam Sultan Agung \\ *ickanurjanah98@gmail.com
}

\begin{abstract}
ABSTRAK
Kemampuan berfikir kritis matematis merupakan kemampuan berfikir dalam menyelesaikan suatu masalah yang melibatkan pengetahuan, penalaran, dan pembuktian matematika. Namun pada kenyataannya kemampuan berfikir kritis matematis siswa kelas V SD Negari Sembungharjo 01 masih rendah. Tujuan dari pembelajaran ini adalah agar kemampuan berfikir kritis matematis siswa berkembang setelah pembelajaran dengan model collaborative learning berpendekatan open-ended berbantuan media macroflash 8. Penelitian ini menggunakan desain Quasi Experimental Design dengan bentuk pretest-posttest control group design Hasil penelitian menunjukkan bahwa: (1) kemampuan berfikir kritis matematis siswa kelas eksperimen menggunakan model collaborative learning berpendekatan open-ended berbantuan media macroflash 8 lebih baik atau sama terhadap siswa kelas kontrol dengan menggunakan model ekspositori, dibuktikan dengan hasil - $t_{\text {tabel }}(-2,034)$ $\leq t_{\text {hitung }}(1,503) \leq t_{\text {tabel }}(2,034)$ sehingga Ho ditolak dan Ha diterima diartikan terdapat perbandingan nilai pretest dan posttest pada kelas eksperimen dan kelas kontrol pada uji-t. Dalam penelitian ini dapat disimpulkan bahwa setelah diberikan pembelajaran model collaborative learning berpendekatan open-ended terdapat perbedaan hasil dari sebelum dan sesudah pembelajaran terhadap kemampuan berfikir kritis matematis.
\end{abstract}

Kata Kunci: Pembelajaran Collaborative Learning, Open-ended, Macroflash 8, Kemampuan Berfikir Kritis Matematis.

\section{ABSTRACT}

Mathematical critical thinking ability is the ability to think in solving a problem that involves knowledge, reasoning, and mathematical proof. But in reality the ability to think critically mathematic class V SD Negari Sembungharjo 01 students is still low. The purpose of this study is that students' mathematical critical thinking skills develop after learning with a collaborative learning model with open-ended approach assisted by macroflash media 8. This study uses a Quasi Experimental Design design in the form of pretest-posttest control group design The results of the study show that: (1) mathematical critical thinking ability of experimental class students using collaborative learning models with open-assisted macroflash 8 media help is better or equal to control class students using expository models, as evidenced by the results of-table $(-2,034) \leq$ tcount (1.503) $\leq$ table (2.034) so that Ho is rejected and Ha is accepted, it means that there is a comparison between the pretest and posttest values in the experimental class and the control class in the t-test. In this study it can be concluded that after being given a collaborative learning model with openended approach there are differences in the results of before and after learning of mathematical critical thinking skills.

Keywords: Collaborative Learning, Open-ended Learning, Macroflash 8, Mathematical Critical Thinking Ability. 


\section{PENDAHULUAN}

Pada era globalisasi seperti sekarang ini, perkembangan sangat pesat terjadi dan menuntut berbagai kalangan untuk lebih kreatif, terampil, dan inovatif di berbagai bidang yang tentunya membuat sesorang lebih siap menghadapi adanya perkembangan di masa mendatang salah satunya dalam dunia pendidikan. Dalam berbagai konteks pendidikan sendiri memiliki makna yang beragam, (Nofijantie, 2014) menyatakan bahwa "Pendidikan merupakan upaya yang terencana dalam proses pembimbingan dan pembelajaran bagi individu agar berkembang dan tumbuh menjadi manusia yang mandiri, bertanggung jawab, kreatif, berilmu, sehat, dan berakhlak mulia baik dilihat dari aspek jasmani maupun ruhani”. Di Indonesia saat ini pemerintah memberlakukan kurikulum 2013 yang menuntut siswanya agar lebih aktif dalam proses pembelajaran serta mendorong siswa agar berfikir tingkat tinggi sehingga pembelajaran menjadi lebih bermakna bagi siswa. Dalam pelaksanaan kurikulum 2013 diperlukan kreativitas dari guru dalam mengelola pembelajaran seperti penggunaan model, metode, pendekatan, dan media.

Pada kenyataannya banyak guru yang belum melakukan inovasi mulai dari penggunaan model, metode, pendekatan serta media yang beragam dalam proses pembelajaran karena pembelajaran saat ini tidak hanya menuntut pada aspek kognitif saja tetapi harus diimbangi dengan aspek afektif dan psikomotor. Pada aspek kognitif salah Salah satu kemampuan dalam pembelajaran matematika yang harus dimiliki oleh anak adalah kemampuan berfikir kritis matematis. Susanto (2016: 185) mengungkapkan matematika merupakan salah satu disiplin ilmu yang dapat meningkatkan kemampuan berfikir, berargumentasi, memberikan kontribusi dalam penyelesaian masalah sehari-hari. Melalui pembelajaran matematika kemampuan berfikir kritis matematis siswa dapat dikembangkan. Peter (2012:474) mengemukakan kemampuan berfikir kritis matematis merupakan sebuah proses yang mengarah pada penarikan kesimpulan tentang apa yang harus kita percayai dan tindakan yang akan dilakukan. Keterampilan berfikir kritis matematis sangat penting bagi siswa karena dengan keterampilan ini siswa mampu bersikap rasional dan memilih alternatif pilihan yang terbaik untuk dirinya. Selain itu, menanamkan kebiasaan kepada siswa untuk berfikir kritis matematis bagi pelajar perlu dilakukan agar mereka dapat mencermati berbagai persoalan yang ada dan terjadi di dalam kehidupan sehari-hari. Namun di Indonesia kemampuan berpikir kritis matematis masih berada ditingkatan yang rendah dan belum dapat dikuasai dengan baik oleh siswa Indonesia. Hal tersebut dapat dilihat dari hasil penelitian oleh TIMMS (Trends in Internasional Mathematics and Science Study) pada tahun 2011 Adanya fakta hasil TIMMS 2011 pada domain proses kognitif bahwa penalaran siswa Indonesia masih lemah yang hanya berkisar pada $17 \%$ sedangkan ditingkat internasional mencapai $30 \%$ hal ini menjadi indikasi masih lemahnya kemampuan berfikir kritis matematis siswa Indonesia. Oleh karena itu, hasil TIMMS 2011 dapat dijadikan dasar bahwa kemampuan berfikir kritis matematis siswa sekolah dasar di Indonesia memerlukan perhatian khusus.

Berdasarkan hasil wawancara dan observasi dikelas V SDN Sembungharjo 01 yang dilakukan pada tanggal 13 November 2019 didapatkan fakta bahwa kemampuan berfikir kritis matematis siswa berada ditaraf yang rendah dan kurang dikembangkan. Hal ini terlihat dari proses pembelajaran guru masih menggunakan model dan metode konvensional yaitu ekspositori. Banyak siswa yang kurang aktif dalam mengikuti proses pembelajaran. 
Berdasarkan hasil studi dokumentasi didapat bahwa masih banyak siswa yang mendapat nilai rendah dan kesulitan saat mengerjakan soal dalam pembelajaran matematika dikarenakan banyak siswa yang kurang menggunakan daya nalarnya dalam kemampuan berfikir kritis matematis.

Adanya kondisi tersebut diperlukan inovasi dan kreatifitas guru serta penggunaan media pembelajaran yang interaktif dalam mengembangkan proses pembelajaran dengan menerapkan pembelajaran yang mendorong siswa untuk aktif, kreatif dan inovatif. Salah satu alternatifnya adalah menerapkan model collaborative learning dengan pendekatan open-ended berbantuan media macroflash 8. Stahl, et al. (2011) menyebutkan bahwa "collaborative learning involves individuals as group members, but also involves phenomena like the negotiation and sharing of meanings-including the construction and maintenance of shared conceptions of tasks - that are accomplished interactively in group processes." Pembelajaran kolaboratif tidak hanya melibatkan siswa sebagai anggota kelompok tetapi juga melibatkan siswa dalam berbagai pendapat dan kegiatan yang bermakna yang dilakukan secara interaktif dalam kelompok. Tujuan dari model pembelajaran collaborative learning yang dilakukan secara berkelompok tidak hanya untuk mencapai persamaan pengetahuan yang diperoleh dalam kegiatan kelompok, karena pembelajaran tersebut dapat mendorong siswa untuk menemukan berbagai pengetahuan, ide maupun informasi yang menyangkut materi dan dikuasai oleh masing-masing anggota dalam kelompok. Jadi siswa dapat mengimplementasikan pemahamannya yang didapat dari berkelompok untuk diaplikasikan ketika dihadapkan secara individu dalam pembelajaran. Dalam penyampaiannya siswa diminta untuk memahami penjelasan materi bangun ruang kubus dan balok dengan cara memperhatikan media interaktif menggunakan aplikasi macromedia flash 8. Guru meminta siswa untuk membentuk kelompok kolaboratif dan mendiskusikan serta bekerja sama dalam menjawab soal terbuka (open-ended). Perberian soal open-ended dalam kelompok kolaboratif bertujuan agar tingkat berfikir kritis matematis siswa semakin terasah karena siswa diarahkan untuk bekerja sama menyelesaikan soal yang mempunyai beragam jawaban. Model collaborative learning memposisikan siswa sebagai pembelajar aktif yang mampu mengonstruksikan pengetahuan mereka sendiri dengan begitu tingkat berfikir kritis matematis siswa dapat dikembangkan.

Peneliti terpikat melaksanakan penelitian dengan judul kemampuan berfikir kritis matematis siswa dengan menggunakan model collaborative learning dengan pendekatan openended berbantuan media macroflash 8 dilaksanakan pada siswa kelas V SDN Sembungharjo 01. Dengan tujuan untuk mengetahui apakah kemampuan berfikir kritis matematis siswa menggunakan model collaborative learning dengan pendekatan open-ended berbantuan media macroflash 8 lebih baik dibandingkan dengan model ekspositori.

\section{METODE}

Peneliti menggunakan metode kuantitatif eksperimen. Sugiono (2015: 107) mengemukakan bahwa untuk mencari tahu pengaruh suatu treatmen yang dilakukan dengan keadaan kondisi terkendali merupakan makna dari sebuah eksperimen. Desain quasi eksperimental design dengan bentuk pertest-posttest control group design adalah desai yang diterapkan dalam penelitian ini. Dalam pelaksanaannya hanya satu kelompok yang diberi perlakuan dengan cara pemberian pretest sebelum adanya perlakuan dan posttest setelah adanya 
perlakuan. Perlakuan yang diberikan berupa model collaborative learning dengan pendekatan open-ended berbantuan media macroflash 8.

Jumlah populasi dalam penelitian ini adalah seluruh siswa kelas V SDN Sembungharjo 01 yang berjumlah 83 siswa. Peneliti menggunakan rumus Slovin untuk mengetahui banyaknya sampel yang digunakan dalam penelitian ini. Sampel yang digunakan adalah simple random sampling dan diperoleh 69 siswa yang terbagi atas 35 siswa kelas eksperimen dan 34 siswa kelas kontrol.

Instrumen yang digunakan dalam penelitian ini adalah soal tes untuk menguji kemampuan berfikir kritis matematis siswa, studi dokumentasi dan wawancara. Afandi (2018: 67) menyatakan bahwa tes berfungsi untuk mengukur sejauh mana kemampuan siswa dalam memahami pembelajaran yang telah disampaikan. Soal tes terlebih dahulu diuji validitas, reliabilitas, daya pembeda dan tingkat kesukaran. Dari 10 soal berbentuk uraian yang telah diuji tersebut terdapat 8 soal yang valid dan 2 soal yang tidak valid. Soal yang valid kemudian dijadikan untuk menguji pretest dan posttest.Studi dokementasi digunakan untuk mengetahui daftar nama siswa, hasil pekerjaan siswa serta wawancara ditujukan sebagai intrumen pendukung.

Teknik analisis data yang digunakan untuk menguji nilai pretest dan posttes pada penelitian ini mengguanakan teknik statistika berupa uji normalitas, uji homogenitas, uji kesamaan dua tara-rata serta uji hipotesis.

\section{HASIL DAN PEMBAHASAN}

Proses pelaksanaan penelitian dilakukan selama lima kali pertemuan dengan pertemuan pertama membagikan pretest terlebih dahulu, pemberian perlakuan selama tiga hari selanjutnya diakhiri dengan posttest dihari terakhir. Sesuai dengan hasil penelitian dan analisis data yang telah dilakukan didapatkan bahwa terdapat perbedaan kemampuan berfikir kritis matematis menggunakan model collaborative learning dengan pendekatan open-ended berbantuan media macroflash 8 pada siswa kelas V SDN Sembungharjo 01. Hal ini sesuai dengan hasil analisis data pretest dan posttest yang telah dilakukan. Berikut merupakan tabel nilai rata-rata kemampuan berfikir kritis matematis siswa sebelum diberi perlakuan (pretest) dan sesudah diberi perlakuan (posttest).

Tabel 1. Nilai Rata-rata Kemampuan Berfikir Kritis Matematis Siswa

\begin{tabular}{ccc}
\hline No & Perlakuan & Nilai Rata-rata \\
\hline 1. & Pretest & 53,48 \\
2. & Posttest & 80,03 \\
\hline
\end{tabular}

Berdasarkan Tabel 1, rata-rata nilai pretest sebesar 53,48 dan rata-rata nilai posttest sebesar 80,03 . Terlihat terdapat perbedaan pada rata-rata nilai kemampuan berfikir kritis matematis siswa sebelum diberi perlakuan (pretest) dan setelah diberi perlakuan (posttest) menggunakan model collaborative learning dengan pendekatan open-ended berbantuan media macroflash 8.

Data yang diperoleh peneliti kemudian diolah menggunakan analisis data awal dan akhir. Bertumpu pada analisis data awal (pretest) diolah dengan menggunakan uji liliefors dengan 
bantuan program excel didapatkan hasil output yang menunjukkan bahwa data berdistribusi normal dengan $\mathrm{L}_{\text {maks }}=0,865$ dan $\mathrm{L}_{\text {tabel }}=1,7$ pada kelas eksperimen dan $\mathrm{L}_{\text {maks }}=0,952$ dan $\mathrm{L}_{\text {tabel }}=1,65$ pada kelas kontrol. Nilai tersebut sesuai dengan $\mathrm{L}_{\text {maks }}<\mathrm{L}_{\text {tabel }}$, maka data berdistribusi normal. Tabel 2 merupakan hasil analisis normalitas data awal.

Tabel 2. Uji Normalitas Data Awal

\begin{tabular}{ccccc}
\hline Variabel & Jumlah Sampel & $\mathbf{L}_{\text {maks }}$ & $\mathbf{L}_{\text {tabel }}$ & Keterangan \\
\hline $\begin{array}{c}\text { Hasil ulangan harian kelas } \\
\text { eksperimen (pretest) }\end{array}$ & 35 siswa & 0,865 & 1,7 & Berdistrisbusi normal \\
$\begin{array}{c}\text { Hasil ulangan harian kelas } \\
\text { kontrol (pretest) }\end{array}$ & 34 siswa & 0,952 & 1,65 & Berdistrisbusi normal \\
\hline
\end{tabular}

Pada tahap analisis data akhir pada penelitian ini menggunakan uji liliefors dengan bantuan program excel dengan tujuan untuk mengetahui bahwa data tersebut berdistribusi normal atau tidak dan menguji hipotesis yang telah dirumuskan dengan mengolah data nilai posttest. hasil output yang menunjukkan bahwa data berdistribusi normal dengan $\mathrm{L}_{\text {maks }}$ sebesar 0,759 dan $\mathrm{L}_{\text {tabel }}$ sebesar 1,7 pada kelas eksperimen dan $\mathrm{L}_{\text {maks }}$ sebesar 0,642 dan $\mathrm{L}_{\text {tabel }}$ sebesar 1,65 pada kelas kontrol. Nilai tesebut sesuai dengan $\mathrm{L}_{\text {maks }}<\mathrm{L}_{\text {tabel }}$, maka data berdistribusi normal. Tabel 3 merupakan hasil analisis normalitas data akhir.

Tabel 3. Uji Normalitas Data Akhir

\begin{tabular}{ccccc}
\hline Varibel & Jumlah Sampel & $\mathbf{L}_{\text {maks }}$ & $\mathbf{L}_{\text {tabel }}$ & Keterangan \\
\hline $\begin{array}{c}\text { Hasil ulangan harian kelas } \\
\text { eksperimen (pretest) }\end{array}$ & 35 siswa & 0,759 & 1,7 & Berdistrisbusi normal \\
\hline $\begin{array}{c}\text { Hasil ulangan harian kelas } \\
\text { kontrol (pretest) }\end{array}$ & 34 siswa & 0,642 & 1,65 & Berdistrisbusi normal \\
\hline
\end{tabular}

Setelah diketahui data awal dan data akhir berdistribusi normal maka selanjutnya dilakukan uji hipotesis. Uji hipotesis pada penelitian ini menggunakan uji-t dengan menggunakan program excel. Hasil dapat dilihat pada Tabel 4.

Tabel 4. Uji Hipotesis Menggunakan Uji-T

\begin{tabular}{cccc}
\hline \multirow{2}{*}{ No } & \multirow{2}{*}{ Kriteria Data } & \multicolumn{2}{c}{ Uji Kesamaan Dua Rata-rata } \\
\cline { 3 - 4 } & & Eksperimen & Kontrol \\
\hline 1. & Jumlah siswa & 35 & 34 \\
2. & Skor rata-rata & 80,542 & 63,852 \\
3. & Simpangan baku & 85,003 & 87,003 \\
4. & $\mathrm{S}_{\text {gabungan }}$ & \multicolumn{2}{|}{6,09} \\
5. & $\mathrm{T}_{\text {hitung }}$ & \multicolumn{2}{c}{1,503} \\
6. & $\mathrm{T}_{\text {tabel }}$ & \multicolumn{2}{c}{2,034} \\
\hline
\end{tabular}

Berlandaskan pada hasil uji-t diatas, dapat terlihat bahwa terdapat perbedaan kemampuan menyelesakan soal berfikir kritis matematis kelas eksperimen dan kelas kontrol setelah adanya perlakuan (posttest). Perbedaan sangat terlihat pada kelas yang diberi perlakuan dengan menggunakan model collaborative learning dengan pendekatan open-ended berbantuan media macroflash 8 . Dengan ketentuan $-\mathrm{t} \leq t_{\text {hitung }} \leq t_{\text {tabel }}$ dengan hasil $-2,034 \leq-1,503 \leq 2,034$ maka 
$H_{0}$ ditolak dan $H_{a}$ diterima. Hal ini menunjukkan kemampuan berfikir kritis matematis siswa dengan menngunakan model collaborative learning dengan pendekatan open-ended berbantuan media macroflash 8 lebih baik atau sama dengan kemampuan berpikir kritis siswa menggunakan model ekspositori.

Adanya perbedaan dalam kemampuan menyelesaikan masalah soal berfikir kritis matematis dikarenakan penggunaan model collaborative learning dengan pendekatan openended berbantuan media macroflash 8. 'Ayon (2013:16) mengemukakan bahwa model collaborative learning dapat memberikan manfaat kepada siswa karena mengembangkan komunikasi dalam kelompok, siswa dapat mengevaluasi dan mensintesis informasi, melatih kemampuan berfikir kritis matematis, pemahaman intrapersonal dalam berkomunikasi. Model pembelajaran ini merupakan model pembelajaran yang berpusat kepada siswa, guru hanya sebagai fasilitator dan evaluator. Pada proses pembelajarannya siswa diminta untuk berdiskusi secara kolaboratif mengenai topik ataupun materi pembelajaran kemampuan berfikir kritis matematis. Dengan dibentuknya kelompok kolaboratif akan mendorong siswa dalam bekerja sama dan menemukan jalan keluar dari permasalahan secara bersama-sama. Dengan adanya pertukaran pikiran yang terjadi pada saat berkekolompok akan menambah wawasan pengetahuan siswa. Siswa terlatih untuk menggunakan kemampuan berfikir kritis matematisnya dalam kelompok kolaboratif serta dalam menyelesaikan soal terbuka (open-ended). Dengan adanya pemberian masalah berupa soal terbuka siswa akan lebih tertantang dalam mencari alternatif jawaban lain. Penggunaan media berbasis flash yaitu macromedia flash 8 menambah antusisas dan semangat siswa dalam mengikuti proses pembelajaran.

Adanya pengaruh dari model collaborative learning dengan pendekatan open-ended berbantuan media macroflash 8 juga dapat dilihat dari hasil persentase pencapaian indikator kemampuan berfikir kritis matematis yang meliputi menganalisis dan mendiskusikan ruang lingkup masalah, mengumpulkan dan menilai informasi yang relevan, merangkai hubungan antara bagian yang membedakan permasalahan, menilai langkah-langkah penyelesaian yang telah ditentukan. Pencapaian indikator kemampuan berfikir kritis matematis dapat dilihat melalui diagram berikut ini.

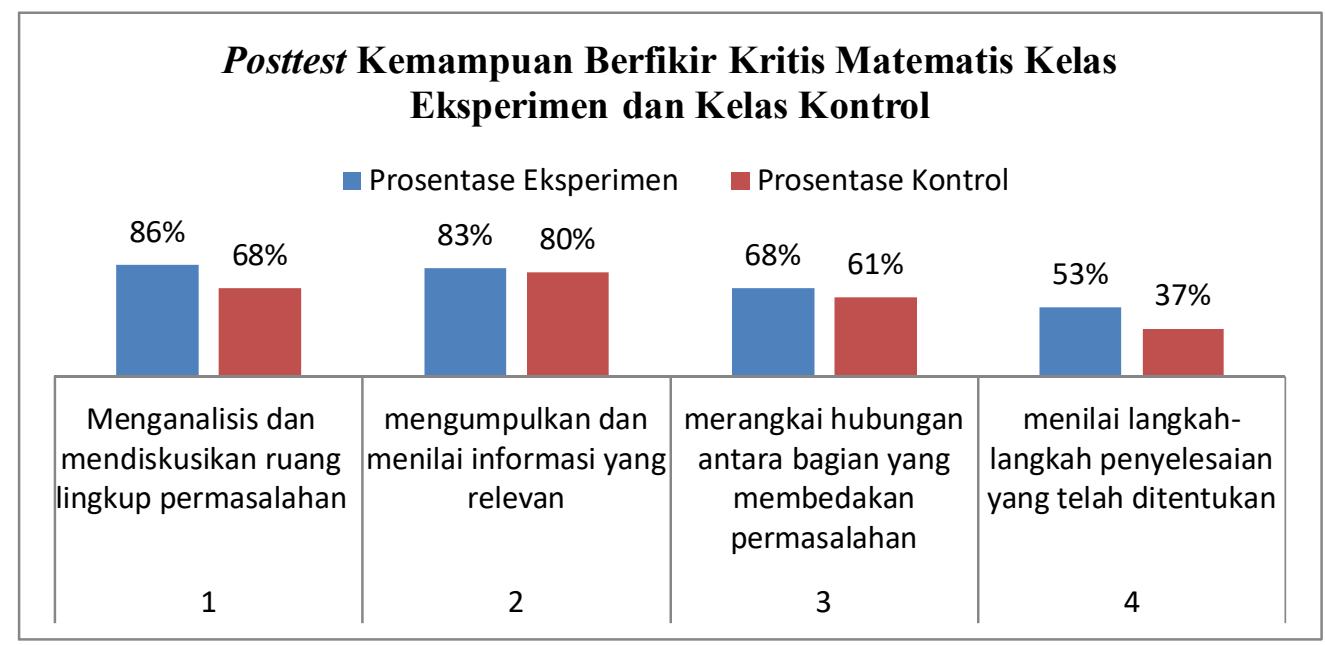

Gambar 1. Presentase Kemampuan Berfikir Kritis Metematis Siswa Pada Posttest 
Berdasarkan hasil pada Gambar 1, dapat dilihat bahwa setelah adanya perlakuan terdapat perbedaan pada pencapaian indikator kemampuan befikir kritis matematis. Pada indikator menganalisis dan mendiskusikan ruang lingkup permasalahan kelas eksperimen sebesar 86\% sedangkan kelas kontrol $68 \%$. Pada indikator mengumpulkan dan menilai informasi yang relevan kelas eksperimen $83 \%$ sedangkan kelas kontrol $80 \%$. Pada indikator merangkai hubungan antara bagian yang membedakan permasalahan kelas eksperimen $68 \%$ dan kelas kontrol $61 \%$ dan pada indikator menilai langkah-langkah penyelesaian yang telah ditentukan kelas eksperimen 53\% sedangkan kelas kontrol 37\%. Hal ini menunjukkan bahwa penggunaan dari model collaborative learning dengan pendekatan open-ended berbantuan media macroflash 8 lebih baik dibandingkan dengan penggunaan model konvensional yaitu model ekspositori pada proses pembelajaran.

\section{SIMPULAN}

Berlandaskan pada pengolahan hasil data pada hasil penelitian dan pembahasan yang telah dilakukan oleh peneliti dapat ditarik kesimpulan bahwa: kemampuan berfikir kritis matematis siswa menggunakan model collaborative learning dengan pendekatan open-ended berbantuan media macroflash 8 lebih baik dibandingkan kemampuan berfikir kritis matematis siswa menggunakan model konvensional yaitu model ekspositori pada siswa kelas V SDN Sembungharjo 01. Adanya pengaruh penggunaan model collaborative learning dengan pendekatan open-ended berbantuan media macroflash 8 membuat peneliti memberikan saran agar model tersebut dapat digunakan oleh guru dalam mengembangkan kemampuan berfikir kritis matematis siswa. Mengingat siswa di era pendidikan saat ini dituntut untuk memiliki kemampuan berfikir tingkat tinggi salah satunya adalah kemampuan berfikir kritis matematis.

\section{DAFTAR PUSTAKA}

Afandi, M. (2018). Teori dan Praktik Penelitian Tindakan Kelas. Semarang: Unissula Press.

Ayon, N. S. (2013). "Collaborative learning in English for specific purposes ( ESP) courses : Effectiveness and students 'attitudes towards it". International Journal of Business and Economic Development, 1(3), 95-108.

Nofijantie, L. (2014). “Peran Lembaga Pendidikan Formal Sebagai Modal Utama Membangun Karakter Siswa”. Jurnal Ilmu Tarbiyah. 3(1), 45-71.

Peter, E.(2012). "Critical Thinking: Essence for Teaching Mathematics and Mathematics Problem Solving Skills", African Journal of Mathematics and Computer Science Research, 5, 39-43.

Stahl, G., et al. (2011) "Computer-Supported Collaborative Learning: An Historical Perspective”. Dalam Cambridge Handbook of the Learning Sciences [Online], 409-26. Tersedia: https://doi.org/10.1145/1124772.1124855 [diunduh 12 Januari 2019]

Sugiono. (2015). Metode Penelitian Pendidikan. Bandung: Alfabeta.

Susanto, A. (2016). Teori Belajar dan Pembelajaran di Sekolah Dasar. Jakarta: Kencana. 